\title{
The Longitudinal Chronic Kidney Disease Study: A Prospective Cohort Study of Predialysis Renal Failure
}

\author{
Rachel L. Perlman, ${ }^{\star}$ Margaret Kiser, $\nmid$ Fredric Finkelstein, $\ddagger$ George Eisele,§ Erik Roys, $\uparrow$ \\ Lei Liu, Sally Burrows-Hudson,\# Friedrich Port, ${ }^{\star \star}$ Joseph M. Messana, ${ }^{*}$ George Bailie,§ \\ Sanjay Rajagopalan, $† \dagger$ and Rajiv Saran** \\ *Division of Nephrology, Department of Internal Medicine, University of Michigan, Ann Arbor, Michigan, \\ †Division of Nephrology, Department of Internal Medicine, University of North Carolina-Chapel Hill, Chapel Hill, \\ North Carolina, ¥Yale Medical Group, Yale University, New Haven, Connecticut, §Division of Nephrology, \\ Department of Internal Medicine, Albany Medical College, Albany, New York, 9 Department of Biostatistics, \\ Kidney Epidemiology and Cost Center, School of Public Health, University of Michigan, Ann Arbor, Michigan, \\ \#Amgen, Inc., Thousand Oaks, California, **University Renal Research and Education Association, Ann Arbor, \\ Michigan, and ††Department of Cardiovascular Medicine, University of Michigan, Ann Arbor, Michigan
}

\begin{abstract}
Chronic kidney disease (CKD) is a significant public health problem: every year the number of Americans living with CKD and requiring renal replacement therapy increases. In addition, individuals with CKD have substantially increased morbidity and mortality compared to the general population. The Longitudinal Chronic Kidney Dialysis (LCKD) Study is a multicenter, prospective, observational study of patients with moderate to severe CKD that was designed to better describe the course of the disease and the determinants of patient

outcomes. Patients with moderate to severe CKD (glomerular filtration rate $[\mathrm{GFR}]<60 \mathrm{ml} / \mathrm{min} / \mathrm{m}^{2}$ ) from four academic nephrology clinics were enrolled between 2000 and 2002. Special cardiac and vascular testing has recently commenced as phase II of this study. Areas that have been or are currently being studied include anemia management, health-related quality of life (HRQOL), medication use, and markers of cardiovascular disease. This article describes the LCKD Study in the context of current knowledge of CKD.
\end{abstract}

The incidence and prevalence of both chronic kidney disease (CKD) and end-stage renal disease (ESRD) continue to increase; kidney disease is a burden to patients and their families and is costly to the health care system. In addition, patients with CKD have a mortality rate significantly higher than the general population (1). Data from the National Health and Nutrition Examination Survey estimate that more than 7 million Americans have a glomerular filtration rate (GFR) less than $60 \mathrm{ml} / \mathrm{min} / 1.73 \mathrm{~m}^{2}$ and 700,000 individuals have a GFR $<30 \mathrm{ml} / \mathrm{min} / 1.73 \mathrm{~m}^{2}$ (2). In 2001 more than 96,000 patients developed ESRD; the incidence rate (per million) of ESRD has been steadily increasing over the last two decades and by about $5 \%$ per year over the past 5 years (1). Diabetes remains the most common etiology of renal failure, accounting for nearly $45 \%$ of patients who start dialysis. Hypertension is the second most frequent cause of ESRD, followed by glomerulonephritis and cystic kidney disease (1).

Address correspondence to: Rajiv Saran, MD, MS, Division of Nephrology, University of Michigan, Kidney Epidemiology and Cost Center, 315 W. Huron, Suite 240, Ann Arbor, Ml 48103-4262, or e-mail: rsaran@umich.edu.

Seminars in Dialysis-Vol 16, No 6 (November-December) 2003 pp. 418-423
There is significant evidence that better control of blood pressure, especially with the use of angiotensinconverting enzyme (ACE) inhibitors, can delay the need for dialysis, both among diabetic and nondiabetic CKD patients (3-5). There is also support for the notion that optimal pre-ESRD care can lead to healthier patients starting dialysis in a more elective fashion, with fewer hospital days and lower morbidity (6).

The Renal Research Institute (RRI) sponsored the Longitudinal Chronic Kidney Disease (LCKD) Study in the year 2000. The chief purpose of this study was to prospectively follow a cohort of patients with CKD in order to better understand the course of disease and determinants of patient outcomes. This article describes the LCKD study in the context of current knowledge about CKD, highlights several important areas being studied with data available from this cohort, and describes new data that are currently being collected, particularly cardiovascular disease-related parameters and potential biomarkers of disease that merit further study.

\section{Background}

Patients on dialysis represent only a small subset of patients with impaired renal function; many more 
patients with renal disease will never progress to ESRD - nonetheless, they too have substantially increased mortality risk (1). Many other patients are referred to a nephrologist late in the course of their disease, or may even first present to an emergency room with advanced uremic symptoms. This is unfortunate, as late referral has consistently been associated with poor outcomes in patients with CKD (7-9). Although standards of care for patients with CKD have been developed $(10,11)$, it remains uncertain what factors may influence positive outcomes. It is still unclear whether the modification of baseline characteristics, such as nutritional status or anemia, can improve morbidity and mortality. Similarly, although certain interventions such as blood pressure and glycemic control are widely accepted, other factors or practice patterns associated with slower progression of disease and improved quality of life (QOL) remain to be better defined. Research looking at $\mathrm{CKD}$ and improving management prior to the initiation of dialysis is therefore receiving the attention it deserves both in the United States and elsewhere (12-14).

\section{Anemia Management in the CKD Population}

Anemia is a well-recognized and frequent complication of CKD. A body of literature supports the use of anemia treatment in the pre-ESRD population as a means to improve exercise capacity, employment status, QOL, and mortality. The beneficial effect of treatment of anemia on mortality appears to be sustained even after the initiation of dialysis $(15,16)$. Despite these demonstrated benefits, $79 \%$ of patients reach ESRD with a hemoglobin of less than $11 \mathrm{~g} / \mathrm{dl}$ and only $22 \%$ of patients receive erythropoietin (EPO) prior to beginning dialysis (Dialysis Outcomes and Practice Patterns Study [DOPPS], unpublished data).

\section{Health-Related Quality of Life (HRQOL) in CKD}

Standardized instruments exist that are routinely used to assess aspects of HRQOL among patients with chronic illness (17). A recent example of the use of HRQOL assessment in CKD patients can be seen in the African American Study of Kidney Disease and Hypertension Trial (AASK) (18). HRQOL was measured using the often-used and well-validated SF-36 health survey $(19,20)$ in more than 1000 African Americans with mild to moderate CKD (mean GFR $46 \mathrm{ml} / \mathrm{min}$ ). In this population, while physical components of HRQOL were lower when compared with the general population, mental components of HRQOL were similar to the general population.

Aside from the self-explanatory utility of striving to maximize QOL for the sake of individual patients, QOL can also be used as an indicator of the impact of disease burden. CKD patients with low QOL scores are at increased risk for hospitalization and death compared to those with higher QOL scores (21). In addition, patients with CKD also have a high comorbidity burden that affects physical and emotional outcomes. It is, however, not yet well understood what factors contribute to the global state termed "quality of life." Studies of incident dialysis patients show high levels of depression, poor QOL, and a high incidence of anemia and malnutrition $(22,23)$. These descriptions of patients starting dialysis so far from optimal mental and physical health is an ongoing reminder that more attention needs to be focused on the issue of HRQOL in CKD.

\section{Cardiovascular Disease in CKD}

There is a disproportionate burden of cardiovascular disease in patients with ESRD: these patients have a risk of cardiovascular mortality that is 15 times higher than the general population (24). Cardiovascular disease accounts for more than $50 \%$ of all deaths in ESRD patients. According to 1998 U.S. Renal Data System (USRDS) data, $40 \%$ of patients who initiate dialysis have evidence of coronary artery disease based on medical record evidence alone and only $15 \%$ have normal left ventricular function (25). It is speculated that progression of $\mathrm{CKD}$ is inextricably linked to the progression of cardiovascular disease in these patients. This is clearly an area worthy of further investigation. If true, improved management of either condition could impact the progression of the other, possibly leading to more efficient and effective treatment.

\section{Study Hypotheses}

The LCKD Study was designed to test the following questions and related hypotheses:

- What are the factors associated with progression or stability of renal function in the outpatient setting?

- What are the outcomes of patients with CKD followed in the setting of nephrology outpatient clinics and what are the correlates of these outcomes?

- Among those patients that reach dialysis, what factors determine the choice of modality for renal replacement?

- What is the frequency of "healthy start" of dialysis and what are its outcomes compared to "conventional start'?

- What is the magnitude of cardiovascular disease burden in CKD in relation to baseline renal function, and does progression of renal disease correlate with progression of cardiovascular disease determined noninvasively?

\section{Study Methods}

The LCKD Study is a prospective, observational study of patients with moderate to severe CKD (GFR $<50 \mathrm{ml} / \mathrm{min} / 1.73 \mathrm{~m}^{2}$; CKD stages III-V; dialysis and transplant patients are not included). The participants are drawn from four academic nephrology centers: University of Michigan, University of North Carolina, Medical College of Albany, and a Yale Universityaffiliated program. The institutional review boards of the participating centers approved the protocol and all study subjects provided written informed consent. The University of Michigan is the data coordinating center, and 
all statistical analyses are being carried out at the Kidney Epidemiology and Cost Center, Ann Arbor, MI. In October 2000, data from the LCKD study were linked to the Study of Treatment for Renal Insufficiency: Data and Evaluation (STRIDE) Registry (12) in order to extend this observational study to a number of nephrology practices around the country. Data collection instruments for the two studies are identical with the exception of QOL data collection methods. QOL data collection forms were completed by patients directly in the LCKD and administered by telephone interview in the STRIDE Registry.

The LCKD study is being conducted in two phases. Phase I followed 622 patients who enrolled between June 2000 and March 2002. Patients seen in the renal clinics at participating centers with an estimated GFR $\leq 50 \mathrm{ml} /$ $\min / 1.73 \mathrm{~m}^{2}$ using the modified Modification of Diet in Renal Disease (MDRD) Study equation (26) at two separate measurements were invited to participate in the study. Requiring two determinations at least 1 month apart was intended to ensure exclusion of patients who have transient impairment of renal function. This design also allowed inclusion of patients with both timely referral and late referral (i.e., advanced CKD). Participation in this study does not dictate any specific aspects of care, rather its observational nature allows investigators to look for a correlation between the care that is provided and outcomes of interest. At the time of enrollment, patients filled out the SF-36 questionnaire and did so annually thereafter.

Data were abstracted from the medical records by the research coordinators for the initial enrollment visit, including details on comorbidities and medications. In addition, to ensure that data were available for each patient from the time of referral to the nephrology clinic, data were abstracted from the clinic visit when the patient was originally referred to the renal outpatient clinic. Data from follow-up visits were collected by way of a followup questionnaire that recorded any events of significance since the previous visit to the clinic (such as new symptoms, outpatient procedures, or hospitalizations), laboratory data, and medication changes. Follow-up is planned through at least 2004. Demographic and clinical characteristics of study participants are described in Tables 1-4.

Phase II of this study began in January 2003 with the availability of additional funding from the RRI. The chief aim of phase II is to recall sequentially as many patients as possible from the original cohort to enable the investigators at each site to carry out noninvasive cardiovascular studies and collect blood and urine for biomarker studies. At two of the four sites (University of

TABLE 1. Patients enrolled (June 13, 2000-March 1, 2002)

\begin{tabular}{lr}
\hline Site & $N$ \\
\hline All & 622 \\
University of Michigan & 249 \\
Albany Medical Center & 95 \\
New Haven, CT & 133 \\
University of North Carolina & 145 \\
\hline
\end{tabular}

TABLE 2. Patients by CKD stage (GFR range)

\begin{tabular}{lrc}
\hline $\begin{array}{l}\text { Dialysis Outcomes Quality Initiative (DOQI) } \\
\text { GFR }^{\mathrm{a}} \text { stage }\end{array}$ & $N$ & Percent \\
\hline Stage $5\left(<15 \mathrm{ml} / \mathrm{min} / 1.73 \mathrm{~m}^{2}\right)$ & 111 & $20 \%$ \\
Stage 4 $\left(15-29 \mathrm{ml} / \mathrm{min} / 1.73 \mathrm{~m}^{2}\right)$ & 325 & $58 \%$ \\
Stage 3 $\left(30-59 \mathrm{ml} / \mathrm{min} / 1.73 \mathrm{~m}^{2}\right)$ & 126 & $22 \%$ \\
Stage 2 $\left(60-89 \mathrm{ml} / \mathrm{min} / 1.73 \mathrm{~m}^{2}\right)$ & 2 & $<1 \%$ \\
\hline
\end{tabular}

${ }^{\mathrm{a}}$ GFR calculated at enrollment by modified MDRD equation (26).

TABLE 3. Cause of CKD or ESRD

\begin{tabular}{lccr}
\hline Cause & $\begin{array}{c}\text { LCKD } \\
\text { Study } N\end{array}$ & $\begin{array}{c}\text { USRDS 2000 } \\
\text { Percent }\end{array}$ & Percent \\
\hline Diabetes & 205 & $35 \%$ & $45 \%$ \\
Hypertension & 151 & $26 \%$ & $27 \%$ \\
Glomerulonephritis & 49 & $8 \%$ & $9 \%$ \\
Polycystic kidney disease & 29 & $5 \%$ & $2 \%$ \\
\hline
\end{tabular}

a2002 USRDS Annual Data Report, Table C.11.

TABLE 4. Patient characteristics

\begin{tabular}{lc}
\hline Patient characteristics & All patients $(n=622)$ \\
\hline Mean age (years) & 60.4 \\
White & $75 \%$ \\
Male & $56 \%$ \\
Diabetes & $38 \%$ \\
CAD & $27 \%$ \\
Mean hemoglobin & $11.8 \mathrm{~g} / \mathrm{dl}$ \\
Mean albumin & $3.8 \mathrm{~g} / \mathrm{dl}$ \\
Mean GFR & $23.2 \mathrm{ml} / \mathrm{min}$ \\
\hline
\end{tabular}

Michigan and University of North Carolina), this testing is being done in the setting of the site's General Clinical Research Center. It is envisaged that at least 450 patients will enroll in the follow-up cardiac studies. A follow-up cardiac study visit will be organized for each participant 1 year after the first. Meanwhile their clinic follow-up visits will continue to be monitored as in phase I. All data analyses are being conducted at the Kidney Epidemiology and Cost Center, University of Michigan, Ann Arbor, MI.

\section{Preliminary Study Results and Ongoing Projects with the LCKD Study \\ Correlates of GFR at Enrollment}

Variation in the patient's GFR at enrollment may simply reflect a variation in referral practice patterns, but may also be associated with burden of disease comorbidity. We describe the distribution of GFR for patients at enrollment (Table 2). To test the hypothesis that patients with the highest GFR are actually referred to the clinic early due to other complications or comorbidities, such as congestive heart failure, rather than as a practice pattern indicating earlier referral per se, linear regression was used to evaluate possible correlates of enrollment GFR. In preliminary studies, models adjusted for age, race, sex, diabetes, 
hemoglobin, and serum albumin showed enrollment GFR to be correlated with hemoglobin but not with albumin.

\section{Progression of Renal Disease}

Several interventions and patient factors can modify the rate of progression of CKD. Medical interventions include dietary prescription, blood pressure control, angiotensin-converting enzyme (ACE) inhibition, and the treatment of anemia, hyperparathyroidism, hyperphosphatemia, hyperlipidemia, and hyperglycemia. Patient factors include the etiology of underlying renal disease, social support, level of education, age, sex, race, and degree of compliance. Progression of renal disease in this study cohort is being explored for purposes of analysis as the absolute change in GFR from baseline to latest follow-up, change in GFR per month, slope of GFR change, and slope of GFR change divided by mean GFR. It has been recognized that a substantial number of patients are "nonprogressors." Predictors of progression versus nonprogression are being identified in currently ongoing analyses from this cohort.

\section{Anemia Management}

The correction of anemia in CKD patients is likely to impact QOL, morbidity, and mortality. The investigators have sought to identify factors associated with various aspects of anemia management. Descriptive statistics and logistic regression have been used to examine predictors of EPO and iron use. The prevalence of anemia (hemoglobin $<11 \mathrm{~g} / \mathrm{dl}$ ) was $34 \%$ overall. When compared to patients with normal hemoglobin levels $(n=332)$, anemic patients were more likely to have lower albumin and lower GFR $(p<0.0001)$. EPO use among anemic patients was only $20 \%$ and iron was prescribed in only $24 \%$ of the anemic patients. In multivariate analyses $(n=332)$, patients who were diabetic or had cardiac disease, low GFR, or low albumin were more likely to receive EPO. In addition, a strong center effect was noted even among the four academic centers studied, suggesting a difference in practice patterns (27).

\section{Medication Use}

Data regarding the actual use of various medications in patients with CKD are incomplete. Thus the patterns seen in this cohort will be an asset to further study. At enrollment, these CKD patients were taking an average of $7 \pm 4$ medications (range 1-20). The most commonly used class of drugs was ACE inhibitors (53\%) followed closely by $\beta$-blockers $(52 \%)$. Other commonly used drugs or classes of drugs are angiotensin receptor blockers $(22 \%)$, EPO $(30 \%)$, aspirin $(40 \%)$, statins $(17 \%)$, and iron (16\%). GFR, albumin, and hemoglobin were identified as predictors of EPO use using logistic regression. Subsequent studies will evaluate the association of medication use with disease categories and outcomes (28).
Qol

Quality of life was assessed with the SF-36 health survey, a validated tool to measure health-related QOL (17), both at baseline and at follow-up. We hypothesized that the degree of renal insufficiency, level of anemia, and nutritional status as measured with albumin would all influence patient-reported QOL. This study has investigated the association of eight major QOL scales and two summary scores with hemoglobin, albumin, and GFR using linear regression adjusted for age, race, sex, and diabetes. Baseline GFR was not a significant predictor of QOL in this cohort. Baseline hemoglobin and albumin were correlated with QOL, indicating that anemia and nutritional and/or inflammatory status may influence QOL in CKD patients more than GFR does (29).

Follow-up QOL data has allowed us to determine whether, in this cohort, changes in GFR, albumin, and hemoglobin are associated with changes in QOL. Logistic regression was used to determine whether there were significant differences between patients where follow-up QOL data was available versus those where it was not available with respect to age, race, sex, diabetes, coronary artery disease, and EPO use and $t$-tests were performed to compare the mean scores between these two groups. Univariate analysis was used to determine the relationship between change in QOL over time and biochemical markers. Linear regression was used to evaluate predictors of change in QOL adjusted for age, race, sex, diabetes, EPO use, average QOL, and incremental change in GFR, hemoglobin, and albumin. Although there is a common assumption that QOL depends on the degree of renal function, this was not the case in this cohort. By most measurements in the SF-36, $\triangle$ GFR was not correlated with $\Delta$ QOL in the range of GFRs studied. In addition, this study shows that changes in QOL may be influenced by changes in hemoglobin and albumin (30).

\section{Cardiovascular Studies and Biomarker Studies}

In phase II of the LCKD Study, patients from the original cohort are being invited to participate in the cardiovascular component of the study. To analyze the progression of cardiovascular disease, cardiovascular testing will be done on two occasions 1 year apart. The following noninvasive tests are being performed: echocardiogram for left ventricular dimensions and function, flow-mediated vasodilation to assess endothelial function, pulse wave velocity for the assessment of vascular compliance, 24-hour Holter monitoring to assess heart rate variability, caroid intima-media thickness and plague area as a surrogate atherosclerosis and spiral computed tomography to quantify the degree of coronary calcification. In addition, blood and urine samples are being collected and stored for future biomarker studies and genetic testing. A centralized cardiac core has been established at the University of Michigan in close collaboration with the Department of Cardiovascular Medicine. A manual of operations has been created and all site personnel have been trained in the collection of cardiovascular data by similar techniques for quality 
assurance and comparability of data. Periodic visits by personnel from the cardiac core ensure uniform standards of data collection at all sites.

\section{Conclusion}

The LCKD Study has allowed investigators to prospectively follow a cohort of patients with renal disease. In analyzing data from patients from four academic centers we will be able to describe issues related to the progression of CKD as well as the associated cardiovascular disease. In addition, related topics such as mortality, hospitalization and ESRD outcomes, anemia management, medication and resource utilization, and QOL are also being studied. Despite recently published expert consensus opinions, the treatment of renal disease remains highly influenced by local prescribing and treatment patterns.

The LCKD Study along with the STRIDE Registry (12) and the more recently initiated NIH sponsored CRIC Study (31) will provide rich epidemiological insight into various aspects of CKD. These ongoing studies are testimony to the high priority the renal community places on the study of CKD prior to the initiation of the renal replacement therapy. Longitudinal cohort studies are not a substitute for randomized trials; however, they provide a realistic picture of what actually occurs in practice. In addition, via epidemiologic studies, potential weaknesses in current treatment practices-for example, the suboptimal management of anemia with EPO and iron use and the underutilization of ACE inhibitors - can be observed and brought to the attention of practitioners.

Future studies with the LCKD Study data include the important issue of the timing of referral for vascular access and the timing of initiating renal replacement therapy. The patients in this CKD cohort may be identified in other related databases after beginning dialysis. It may be possible to link these data in order to study early (i.e., pre-ESRD) determinants of later (ESRD) success, health, and QOL. We are optimistic the LCKD study will make significant contributions to the field of CKD by identifying practice patterns associated with better outcomes and by generating hypotheses to be tested in future clinical trials, particularly with respect to reducing the burden and progression of both renal disease and cardiovascular disease. This study will therefore become an asset toward further understanding the determinants of successful CKD management.

\section{Acknowledgments}

The Renal Research Institute, New York, NY, and Amgen Inc., sponsored, supported, and funded the LCKD Study. We are immensely grateful for the patience and cooperation of all participating subjects and to the research coordinators and research assistants at each site without whose contribution a multicenter study would be impossible to implement. Specifically
Kerri Briesmeister, Laura Davidson, Bonnie Welliver, Rita Aouad, Christine Kehrer, and Susan Reimann (University of Michigan); Kathy Lambeth and Melissa Caughey (University of North Carolina); Diane DelMonicao, Nancy Sutter, and Susan Rauch (Albany Medical College); and Chrissy Turcio and Marla Marenna (New Haven, CT).

\section{References}

1. U.S. Renal Data System: USRDS 2002 Annual Data Report: Atlas of EndStage Renal Disease in the United States. Bethesda, MD: National Institutes of Health, National Institute of Diabetes and Digestive and Kidney Diseases, 2002

2. Coresh J, Astor BC, Greene T, Eknoyan G, Levey AS: Prevalence of chronic kidney disease and decreased renal function in the adult US population: Third Health and Nutrition Examination Survey. Am J Kidney Dis 41:1-12, 2003

3. The ACE Inhibitors in Diabetic Nephropathy Trial Group: Should all patients with type I diabetes mellitus and microalbuminuria receive angiotensin-converting enzyme inhibitors? Ann Intern Med 134:370-379, 2001

4. Kshirsagar AV, Joy MS, Hogan SL, Falk RJ, Colindres RE: Effect of ACE inhibitors in diabetic and nondiabetic chronic renal disease: a systematic review of randomized placebo-controlled trials. Am J Kidney Dis 35:695-707, 2000

5. Jafar TH, Schmid CH, Landa M, Giatras I, Toto R, Remuzzi G, Maschio G, Brenner BM, Kamper A, Zucchelli P, Becker G, Himmelmann A, Bannister K, Landais P, Shahinfar S, de Jong PE, de Zeeuw D, Lau J, Levey AS: Angiotensin-converting enzyme inhibitors and progression of nondiabetic renal disease. Ann Intern Med 135:73-87, 2001

6. Pereira BJ: Optimization of pre-ESRD care: the key to improved dialysis outcomes. Kidney Int 57:351-365, 2000

7. Stack AG: Impact of timing of nephrology referral and pre-ESRD care on mortality risk among new ESRD patients in the United States. Am J Kidney Dis 41:310-318, 2003

8. Kinchen KS, Sadler J, Fink N: The timing of specialist evaluation in chronic kidney disease and mortality. Ann Intern Med 137:479-486, 2002

9. Avorn J, Bohn RL, Levy E, Levin R, Owen WF, Winkelmayer WC, Glynn RJ: Nephrologist care and mortality in patients with chronic renal insufficiency. Arch Intern Med 162:2002-2006, 2002

10. National Kidney Foundation: Executive summary. In: K/DOQI Clinical Practice Guidelines for Chronic Kidney Disease. New York: National Kidney Foundation, 2002

11. European best practice guidelines in nephrology. Nephrol Dial Transplant 14(suppl 5):1-50, 1999

12. Rao M, Kausz AT, Mitchell D, Ratican SH, Lin F, Burrows-Hudson S, Port F, Pereira BJ: The study of treatment for renal insufficiency: data and evaluation (STRIDE), a national registry of chronic kidney disease. Semin Dial $15: 366-369,2002$

13. Wright TJ, Kusek JW, Toto RD, Lee JY, Agodoa LY, Kirk KA, Randall OS, Glassock R: Design and baseline characteristics of participants in the African American Study of Kidney Disease and Hypertension (AASK) pilot study. Control Clin Trials 17(4 suppl):S3-S16, 1996

14. Jager KJ, Merkus MP, Boeschoten EW, Dekker FW, Stevens P, Krediet RT, NECOSAD Study Group: Dialysis in the Netherlands: the clinical condition of new patients put into a European perspective. Nephrol Dial Transplant 14:2438-2444, 1999

15. Xue JL, St. Peter WL, Ebben JP, Everson SE, Collins AJ: Anemia treatment in the pre-ESRD period and associated mortality in elderly patients. Am J Kidney Dis 40:1153-1161, 2002

16. Fink JC, Blahut SA, Reddy M, Light PD: Use of erythropoietin before the initiation of dialysis and its impact on mortality. Am J Kidney Dis 37:348-355, 2001

17. Korevaar JC, Merkus MP, Jansen MA, Dekker FW, Boeschoten EW, Krediet RT, NECOSAD Study Group: Validation of the KDQOL-SF ${ }^{\mathrm{TM}}$ : a dialysis-targeted health measure. Oual Life Res 11:437-447, 2002

18. Kusek JW, Greene P, Wang SR, Beck G, West D, Jamerson K, Agodoa LY, Faulkner M: Level B for the African American Study of Kidney Disease and Hypertension Trial Study Group. Cross-sectional study of health related quality of life in African Americans with chronic renal insufficiency: the African American Study of Kidney Disease and Hypertension trial. Am J Kidney Dis 39:513-524, 2002

19. Ware J, Snow KK, Kosinski M, Gandek B: SF-36 health survey: manual \& interpretation guide. Boston: Health Institute, 1993

20. Ware J, Kosinski M, Keller SD: SF-36 physical and mental health summary scales: a user's manual. Boston: Health Institute, 1994

21. Lopes AA, Bragg-Gresham JL, Satayathum S, McCullough K, Pifer T, Goodkin DA, Mapes DL, Young EW, Wolfe RA, Held PJ, Port FK, 
Worldwide DOPPS Committee: Health-related quality of life and associated outcomes among hemodialysis patients of different ethnicities in the United States: the Dialysis Outcomes and Practice Patterns Study (DOPPS). Am J Kidney Dis 41:605-615, 2003

22. Walters BA, Hays RD, Spritzer KL, Fridman M, Carter WB: Health-related quality of life, depressive symptoms, anemia and malnutrition at hemodialysis initiation. Am J Kidney Dis 40:1185-1194, 2002

23. Korevaar JC, Jansen MA, Merkus MP, Dekker FW, Boeschoten EW Krediet RT: Quality of life in predialysis end-stage renal disease patients at the initiation of dialysis therapy. The NECOSAD Study Group. Perit Dial Int 20:69-75, 2000

24. Levey AS, Beto JA, Coronado BE, Eknoyan G, Foley RN, Kasiske BL, Klag MJ, Mailloux LU, Manske CL, Meyer KB, Parfrey PS, Pfeffer MA, Wenger NK, Wilson PW, Wright JT: Controlling the epidemic of cardiovascular disease in chronic renal disease: What do we know? What do we need to learn? Where do we go from here? Am J Kidney Dis 32:853-906, 1998

25. Foley RN, Parfrey PS, Sarnak MJ: Clinical epidemiology of cardiovascular disease in chronic renal disease. Am J Kidney Dis 32(5 suppl 3):S112-S119, 1998

26. Levey AS, Bosch JP, Lewis JB, Greene T, Rogers N, Roth D: A more accurate method to estimate glomerular filtration rate from serum creatinine: a new prediction equation. Modification of Diet in Renal Disease Study Group. Ann Intern Med 130:461-470, 1999
27. Patel UD, Wright G, Roys EC, Finkelstein F, Kiser M, Eisele G, BurrowsHudson S, Port FK, Saran R: Anemia management among patients with chronic kidney disease. J Am Soc Nephrol 13:761A, 2002

28. Bailie G, Roys EC, Eisele G, Kiser M, Finkelstein F, Wolfe RA, Mason N, Port FK, Burrows-Hudson S, Saran R: Medication use in chronic kidney disease (CKD) patients: analysis of the multicenter longitudinal CKD study. Presented at the National Kidney Foundation Clinical Meetings, Am J Kidney Dis 41:A7, 2003

29. Saran R, Wolfe RA, Roys EC, Wright G, Kiser M, Eisele G, Finkelstein F, Burrows-Hudson S, Port FK: Predictors of quality of life (Qol) in chronic kidney disease (CKD): cross-sectional analysis in the multicenter longitudinal CKD study. J Am Soc Nephrol 13:520A, 2002

30. Perlman R, Roys EC, Finkelstein F, Kiser M, Eisele G, Burrows-Hudson S, Messana J, Port FK, Wolfe RA, Saran R: Quality of life (QOL) in patients with chronic kidney disease (CKD): a longitudinal study. Presented at the National Kidney Foundation Clinical Meetings, Am J Kidney Dis 41:A8, 2003

31. Feldman HI, Appel LJ, Chertow GM, Cifelli D, Cizman B, Daugirdas J, Fink JC, Franklin-Becker ED, Go AS, Hamm LL, He J, Hostetter T, Hsu CY, Jamerson K, Joffe M, Kusek JW, Landis JR, Lash JP, Miller ER, Mohler ER 3rd, Muntner P, Ojo AO, Rahman M, Townsend RR, Wright JT; Chronic Renal Insufficiency Cohort (CRIC) Study Investigators. The Chronic Renal Insufficiency Cohort (CRIC) Study: Design and Methods. J Am Soc Nephrol 14(7 Suppl 2):S148-153, 2003 